\title{
Democracia e participação. Inovações democráticas e trajetória participativa no Brasil
}

TIAGO VENTURA

Universidade do Estado do Rio de Janeiro / Instituto de Estudos SociaIS e Políticos, Rio de JANEIRO- RJ, BRASIL

\begin{abstract}
Resumo
O debate político atual sobre o tema democracia é marcado por questionamentos diversos acerca do funcionamento, da legitimidade social e da efetividade das instituições representativas. Entre as respostas a esses dilemas, convivemos com o surgimento das mais variadas inovações com vistas a ampliar os contornos participativos e deliberativos dos sistemas políticos contemporâneos. O Brasil é pioneiro na criação de tais experiências, tornando-se referência mundial na produção acadêmica sobre o tema e na reprodução de suas experiências em outros países. A maior parte da literatura dedicada a essas inovações concentrou as análises nos processos internos de funcionamento e no seu impacto no ciclo das políticas públicas. Poucas análises abordam essas inovações com base no diálogo com a tradição participativa e na constituição das instituições democráticas nos países. Partindo da análise bibliográfica de estudos clássicos de sociologia e de ciência política brasileira, pretendemos operar essa reconstrução neste ensaio. A principal conclusão deste trabalho é compreender o surgimento dessas experiências como um marco inédito na democratização do espaço público brasileiro, rompendo com a tradição restritiva no tema participação política.
\end{abstract}

Palavras-chave: Democracia. Participação. Inovações democráticas. Trajetória participativa.

\section{Democracy and participation. Democratic innovations and participatory routee in Brazil}

\begin{abstract}
The current political debate on the theme democracy is marked by various questions about the functioning, social legitimacy, and effectiveness of representative institutions. Among the answers to these dilemmas, we see the emergence of the most varied innovations with a view to broaden the participatory and deliberative outlines of the contemporary political systems. Brazil is a pioneer in creating such experiences, it has become a world reference regarding academic research on the theme and reproduction of its experiences in other countries. A large part of the literature devoted to these innovations has focused its analyses on internal functioning procedures and their impact on the public policy cycle. Few analyses address such innovations having the dialogue with the participatory tradition and the constitution of countries' democratic institutions as a basis. Through a bibliometric analysis of classic studies in sociology and Brazilian political science, we aim at providing such reconstruction in this essay. The main conclusion of this paper is grasping the rise of these experiences as an unprecedented milestone in the democratization of the Brazilian public space, breaking with the restrictive tradition on the theme political participation.
\end{abstract}

Keywords: Democracy. Participation. Democratic innovations. Participatory route.

\section{Democracia y Participación. Innovaciones democráticas y trayectoria participativa en Brasil}

\section{Resumen}

El debate político actual sobre el tema de la democracia está marcado por varios cuestionamientos sobre el funcionamiento, la legitimidad social y la efectividad de las instituciones representativas. En medio de las respuestas a estos dilemas, convivimos con el surgimiento de las más variadas innovaciones con el propósito de ampliar los contornos participativos y deliberativos de los sistemas políticos contemporáneos. Brasil es pionero en la creación de tales prácticas, convirtiéndose en un referente mundial en la producción académica sobre el tema y en la reproducción de sus prácticas en otros países. La mayor parte de la literatura dedicada a estas innovaciones concentró los análisis en los procesos internos de funcionamiento y en su impacto en el ciclo de políticas públicas. Pocos análisis abordan esas innovaciones basadas en el diálogo con tradición participativa y en la constitución de las instituciones democráticas en los países. A partir del análisis bibliográfico de estudios clásicos de sociología y de ciencia política brasileña, se pretende llevar a cabo esa reconstrucción en este ensayo. La principal conclusión de este trabajo es comprender el surgimiento de esas prácticas como un marco inédito en la democratización del espacio público brasileño, rompiendo con la tradición restrictiva en el tema de participación política.

Palabras clave: Democracia. Participación. Innovaciones democráticas. Trayectoria participativa. 


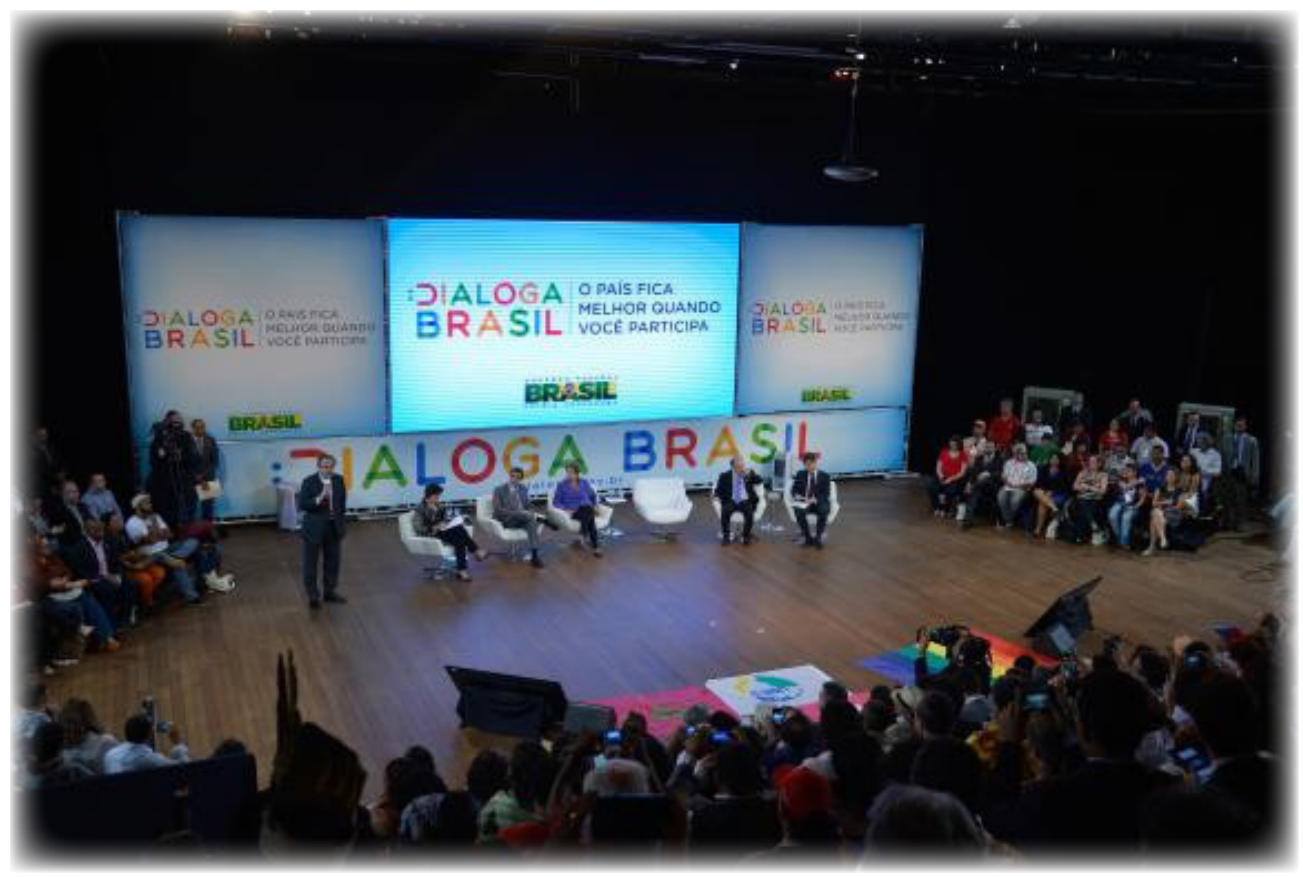

\section{INTRODUÇÃO}

O debate político atual sobre o tema democracia é marcado por questionamentos diversos acerca do funcionamento das instituições representativas. Tal fenômeno é tradicionalmente agrupado em torno da ideia de que vivemos um período de "crise da democracia". Como resposta, convivemos com o surgimento das mais variadas inovações democráticas com vistas a ampliar os contornos participativos e deliberativos dos sistemas políticos contemporâneos. O Brasil é pioneiro na criação de tais experiências, tornando-se referência mundial, sobretudo desde a criação do Orçamento Participativo na cidade de Porto Alegre-RS.

Entendemos o conceito de inovações democráticas (ID) de Smith (2009) como instituições políticas construídas especificamente para ampliar e aprofundar a participação dos cidadãos no processo decisório. Nessa perspectiva, as ID são necessariamente experimentos de caráter institucional, atribuindo à participação do cidadão um papel no processo decisório reconhecido pelas instituições políticas. Nessa perspectiva, tais inovações são vistas como elementos capazes de estabelecer diálogo e aperfeiçoar o funcionamento das tradicionais instituições representativas (SEELE e PERUZZOTI, 2009).

Ao adotarmos tais inovações como elemento central neste ensaio, é importante ressaltar que partimos de uma definição abrangente de participação política que inclua tanto suas características procedimentais ou minimalistas centrada na ocorrência de eleições, no direito ao voto e ao pleno funcionamento de suas instituições representativas (SCHUMPETER, 1984; DAHL, 1971), quanto a possibilidade de concebê-la de forma ampliada a partir de novos canais de participação política exemplificados justamente nessas novas inovações democráticas (PATEMAN, 1970; MANSBRIDGE, 2003; URBINATI, 2006).

Há uma crescente - no âmbito global e nacional - nos estudos sobre esses mecanismos com base em diversas chaves teóricas e com metodologia e objetos de estudo distintos (FUNG e WRIGHT, 2003; AVRITZER, 2009; AVRITZER e SOUZA, 2013; POGREBINSCHI e SANTOS, 2011; MANSBRIDGE e PARKINSON, 2012; SEELE e PERUZZOTI, 2009; GEISSEL e NEWTON, 2012;

\footnotetext{
* Fonte da imagem: Agência Brasil. Disponível em http://agenciabrasil.ebc.com.br/politica/noticia/2015-07/populacao-podera-conversar-comministros-em-nova-plataforma-do-governo. Acesso em 14 mar. 2016.
} 
SMITH, 2009). No entanto, pouco se produziu academicamente com o objetivo de contextualizar de forma precisa a relação entre tais inovações com o contexto, e a trajetória participativa dos países em questão ainda é escassa. Reflexões com este último objetivo podem se tornar elementos centrais para compreender a diversidade dessas inovações.

Por exemplo, porque inovações democráticas semelhantes têm efetividade distinta no ciclo de políticas públicas? Por que em determinados contextos essas inovações têm funcionado de forma mais aberta à sociedade civil e em outros o Estado têm capacidade maior de cooptação dos agentes societais? Por que determinadas inovações democráticas são frequentadas por cidadãos sem prévia participação em setores organizados da sociedade civil ao passo que em outras experiências são ocupadas majoritariamente por movimentos sociais previamente organizados e constituídos? A compreensão dessas questões passa por caminhos diversos. Um primeiro passo proposto neste trabalho é se valer do processo histórico e sociológico de formação da institucionalidade democrática dos países, da relação do Estado com a sociedade civil e do surgimento dessas inovações democráticas em cada contexto nacional para analisar esse fenômeno.

O objetivo deste artigo é dar esse passo no que diz respeito à realidade brasileira. Desvendar a relação entre Estado e sociedade civil no tema participação política e analisar quais elementos históricos e sociológicos resultaram no desenvolvimento de numerosas inovações democráticas no contexto da redemocratização brasileira.

Trata-se, portanto, de um ensaio acadêmico sobre o tema participação no Brasil. Metodologicamente será usada a revisão da bibliografia dedicada a pensar a constituição democrática e da relação entre Estado e sociedade no contexto nacional. Nesse sentido, o artigo está dividido em contextos históricos distintos: a análise do período liberal da República Velha; a constituição do Estado e do corporativismo pós-Revolução de 30; e o período da redemocratização até a atualidade. O esforço empreendido neste trabalho será usar tal bibliografia para refletir sobre a participação política e suas variadas formas experimentadas na contemporaneidade.

\section{O LIBERALISMO EXCLUDENTE DA PRIMEIRA REPÚBLICA}

A Primeira República no Brasil teve como característica central a tentativa de constituir um sistema político e social com raízes fincadas no liberalismo. Tal projeto será marcado pela exclusão da população rural, por limitação à participação política e por forte repressão às tentativas de organização da ação coletiva ligada aos trabalhadores. Seu resultado é a limitação da constituição do Estado como instrumento de mediação das relações políticas da sociedade, em especial relacionadas aos setores empobrecidos.

O ordenamento social nascente na República brasileira não propiciava alterações profundas quando comparado às condições moldadas no Império. Mantinha-se a organização do mundo agrário com base em dois pilares. De um lado, a vedação de nacionais pobres em adquirir a posse da terra, a partir de Lei de Terras de 1850, limitando estruturalmente suas condições de inserção social. Tal realidade, aliada ao passado escravista, impunha a manutenção de precárias condições de vida no campo (CARDOSO, 2010). De outro lado, o ordenamento político organizado pelas elites agrárias exportadoras sustentava-se com base no mandonismo local e no coronelismo: conjugação entre elites locais enfraquecidas e poder público em processo de constituição, em que, de um lado, reforça-se o poder do mandonismo municipal via estruturas estatais e, de outro, amplia-se a dependência do local à dinâmica das elites nacionais (LEAL, 1948).

No outro extremo, como afirma Cardoso (2010), o mundo urbano gerava postos de trabalho insuficientes ao fluxo elevado de imigrantes nacionais e estrangeiros, expondo todos à severidade de mercados de trabalho que ofereciam poucas e más condições de ocupação. Nas palavras do autor: "Na verdade, por muito tempo ainda, o mercado de trabalho urbano, forma capitalista por excelência de distribuição de recursos e posições sociais, não funcionaria como elemento organizador da inscrição social de proporção expressiva dos nacionais" (CARDOSO, 2010, p. 147).

Esse contexto será compreendido por Wanderley Guilherme dos Santos (1979, p. 71) como "a tentativa de organizar a vida econômica e social do país segundo princípios laissez-fairianos ortodoxos". Suas principais características são os limites do Estado na regulação das relações e conflitos entre o capital e o trabalho, nas palavras do autor: "fora da ordem do mercado só existia a 'ordem' da coação" (SANTOS, 1979, p. 73). 
Santos (1979) aponta dois elementos importantes para a compreensão da montagem da estrutura liberal ortodoxa do país nesse período. De um lado, a ortodoxia liberal ficou limitada às questões urbanas, permanecendo intocável a estruturação desigual das relações sociais no agrário brasileiro. Como afirma o autor: "pode-se considerar que a hegemonia ideológica do laissez-faire teve vida curta no Brasil, restrita à área urbana, entre 1888 e 1931, no que concerne à economia, e vulnerada a partir de 1923 no que diz respeito às relações sociais" (SANTOS, 1979, p. 72). De outro, no princípio da década de 1920, inicia-se a produção de leis sociais, como a Eloy Chaves, tensionando o sentido estrito do liberalismo prevalecente. Tal processo indicaria o reconhecimento da insuficiência da atribuição exclusiva ao mercado no provimento de recursos econômicos e sociais às classes populares, como previa a ortodoxia liberal característica do período.

Esse "alargamento" seria, sobretudo, resposta decorrente do processo crescente de organização dos trabalhadores em São Paulo e de sua pressão sobre os setores empresariais, como mostram os dados de Santos (1979) em relação ao crescimento do associativismo no início do século. No entanto, essa tensão da ortodoxia liberal será puramente no plano legal, visto que a marca da resposta estatal será a não efetividade das conquistas sociais. Os principais elementos dessa chave de compreensão da Primeira República também estarão presentes em Vianna (1999). Para o autor, o liberalismo brasileiro foi concebido baseado nos interesses das elites dirigentes agroexportadoras, materializada na Constituição de 1891, conjugando interesses da União com federalismo excludente e intervencionismo discricionário. Nesse sentido, ao manter intacta a estrutura arcaica das relações de trabalho e a proteção dos privilégios de exportação das elites rurais, os pequenos esgarçamentos da legislação trabalhista, ao qual o autor agrega a análise de Santos (1979) e a Lei de Sindicalização de 1907, não ameaçarão o liberalismo brasileiro.

Portanto, para Vianna (1999), mesmo diante de conquistas resultantes da mobilização coletiva do operariado, o cenário das relações entre Estado e sociedade na primeira fase da formação brasileira teve como característica fundamental a criminalização e o não reconhecimento das conquistas legais dos setores subalternos. A dinâmica era baseada no caráter de controle social no mundo urbano e coronelismo no mundo rural. É um clássico exemplo do conflito da constituição do Estado brasileiro no tema participação política e social, no qual o polo restritivo, a partir das estruturas oficiais, impõe-se.

A principal consequência desse quadro, como afirma Cardoso (2010), é a aproximação da ação sindical das práticas enquadradas como crime e desordem. Portanto, a ação política do trabalhador brasileiro, na tentativa de vocalizar interesses coletivos na arena pública, não conseguiu romper a ortodoxia liberal e a indiferença das elites republicanas aos destinos das classes subalternas (CARDOSO, 2010, p. 176). O foco das elites dirigentes era a manutenção da realidade no campo e a ortodoxia liberal nas áreas urbanas.

Portanto, a chave para a compreensão social e política da Primeira República, articulada por autores como Santos (1979), Vianna (1999) e Cardoso (2010), conjuga a orientação liberal, materializada na ausência do Estado na regulação do conflito entre capital e trabalho e na garantia de direitos sociais, e a restrição à participação, via manutenção de estruturas clientelistas de dominação político-social. Como resultado fundamental, a construção republicana no Brasil retardou a formação das instituições e da política como local de mediação de interesses.

O plano da competição eleitoral é um dos exemplos cruciais da dinâmica estabelecida entre Estado-sociedade na Primeira República. Para ter direito a voto era preciso ter mais de 21 anos e ser alfabetizado. Não votavam mulheres, mendigos, praças, religiosos sujeitos a voto de obediência e estrangeiros.

Apesar de não haver dados detalhados sobre o comparecimento eleitoral nesse período, Nicolau (2012) aponta os seguintes números para as eleições presidenciais, tendo como base a população total: 1910 (3\%), 1914 (5\%), 1918 (1,5\%), 1919 (1,5\%), 1922 (4\%), 1926 (2\%) e 1930 (5\%), ou seja, a média de participação eleitoral tinha sido de, aproximadamente, 3\% da população brasileira.

Um elemento importante apontado por Nicolau (2012) é a comparação com os cidadãos que podiam se alistar eleitoralmente. Com base nos Censos de 1900 e 1920, a taxa de alfabetização manteve-se estável em 35\%. Um exemplo do autor é a cidade do Rio de Janeiro, onde era possível se alistarem 163 mil homens, mas só o fizeram 20 mil. Em síntese, apenas $16 \%$ dos homens alistáveis se inscreveram eleitoralmente.

Os baixos índices de comparecimento eleitoral aliados aos dados diminutos da inscrição eleitoral são uma face da fraqueza da legitimidade do Estado diante dos nacionais. Como aponta o autor, "os indivíduos que não fossem vinculados 
a determinados grupos políticos não se sentiam motivados a coletar seus documentos e requisitar a inscrição como eleitor" (NICOLAU, 2012, p. 61).

O Estado, portanto, não aparecia aos nacionais como espaço de construção do público, da vontade geral da população e como mediador das relações políticas, impondo-se só via restrição em relação à participação política da sociedade. A passagem do regime imperial ao republicano no Brasil não teve como consequência a alteração no padrão participativo da sociedade brasileira. A tônica manteve-se na exclusão daqueles agentes societários desprivilegiados de recursos econômicos e políticos.

\section{A CONSTRUÇÃO DO CORPORATIVISMO NO BRASIL}

Como já mencionamos, a ênfase da constituição do Estado ao longo da Primeira República se deu com base na representação dos interesses econômicos das elites agrárias e nos limites à ação coletiva dos setores subalternos. A Revolução de 30 representa a crise desse modelo, em especial como resultado de conflitos no interior das elites exportadoras, entre as beneficiadas pelo federalismo excludente da Primeira República, e as oligarquias não exportadoras em aliança com novos atores sociais do período, entre eles camadas médias urbanas, burguesia industrial e juventude militar. A novidade desse cenário é a consolidação do papel do Estado, sobretudo do Poder Executivo, como elemento fundamental na construção das instituições republicanas no país, em um modelo de desenvolvimento centrado na indústria, no setor urbano e na forte presença estatal. Como aponta Boschi (2010), tais características serão a marca do desenvolvimentismo brasileiro inaugurado na década de 1930, mantendo certa identidade até as reformas neoliberais operadas no Brasil, a partir da década de 1990.

Nessa conjuntura de consolidação e fortalecimento do Estado, duas dinâmicas moldaram sua relação com os agentes societários: a consolidação de direitos da lógica da profissionalização, conceituada por Santos (1979) como cidadania regulada, e a criação de estruturas corporativas de mediação e representação de interesses tanto das classes trabalhadoras quanto do empresariado.

O conceito de cidadania regulada é fundamental para a compreensão do projeto varguista de inclusão política e social. Por mais que houvesse, como fruto da luta sindical, políticas sociais aprovadas ao longo da Primeira República, em decorrência de sua não materialidade coube às práticas legais e culturais articuladas em torno do conceito de cidadania regulada incluir efetivamente a questão social como elemento-chave na construção do Estado.

Nas palavras de Wanderley Guilherme dos Santos (1979, p. 68):

Por cidadania regulada entendo o conceito de cidadania cujas raízes encontram-se, não em um código de valores políticos, mas em um sistema de estratificação ocupacional, e que tal sistema de estratificação ocupacional é definido por norma legal. Em outras palavras, são cidadãos todos aqueles membros da comunidade que se encontram localizados em qualquer uma das ocupações reconhecidas e definidas por lei.

Nesse contexto, a cidadania consistia no conjunto de direitos associados a determinada profissão regulamentada pelo Estado. Tal noção é diversa de uma concepção de universalidade em que o elemento central é o pertencimento a alguma comunidade política. Cardoso (2010) destaca que o pertencimento à cidadania regulada era um momento efêmero, poroso, que aparecia como factível aos nacionais que se qualificassem para ingressar nas profissões regulamentadas pelo Estado. Dessa forma, estabelecia-se um continuum entre incluídos e excluídos, ou entre cidadãos e pré-cidadãos, em que se tornou factível ao excluído acessar a cidadania.

Diferentemente da Primeira República, quando a luta por direitos esbarrava na ausência do Estado na garantia de direitos sociais, a dinâmica da cidadania regulada legitimava a reivindicação por direitos na qual o público passa a aparecer como arena da expressão dessa disputa.

A segunda face da relação Estado-sociedade na era desenvolvimentista é a construção de estruturas corporativas como instrumento de representação e mediação de interesses dos atores societais. Segundo Boschi e Diniz (1991), a tradição corporativa deve ser compreendida como instituições montadas com base na intermediação de interesses com base em um 
ordenamento hierárquico de grupos ou categorias funcionais, lastreado em critérios de filiação ou contribuição compulsória, bem como no monopólio da representação e dirigidos fundamentalmente à burocracia estatal.

Ainda segundo os autores, no caso brasileiro, o corporativismo se estabeleceu com marcos específicos: coincidiu com o fechamento crescente do sistema político a partir da extinção dos partidos e do fechamento do Congresso em 1937; e foi introduzido a partir de uma política deliberada das elites ocupantes do Estado, com o intuito de inserir novos atores sociais, desarticulando suas antigas associações, em especial dos trabalhadores.

Nesse sentido, um dos traços mais importantes do corporativismo brasileiro é seu aspecto diferencial no que diz respeito à relação com o empresariado e com o operariado. Como aponta Boschi (2010, p. 90):

No caso do operariado prevaleceram o controle e a impossibilidade de organização fora da estrutura oficial, levando a uma multiplicidade de sindicatos de bases locais e a uma fragmentação dos órgãos de cúpula quando esse controle se atenua no âmbito da organização das centrais sindicais. No caso do empresariado, a fragmentação se expressou na criação de associações paralelas à estrutura oficial em um ritmo crescente desde o início do ciclo, o qual se intensifica durante os anos 50 e, particularmente, entre os anos 1970 e 1980.

Na argumentação de Boschi (2010), esse contexto gerou um modelo excludente de corporativismo no Brasil, denominado pela literatura como bifronte ou estatal, em contraposição ao modelo baseado nas experiências neocorporativas dos socialdemocratas na Europa.

Vanda Maria Ribeiro Costa (1999) segue argumentação semelhante para discutir a construção do corporativismo no Brasil. A autora aponta que os sindicatos passaram de organizações de defesa de interesses para mecanismos de organização e controle das reivindicações das classes operárias, tendo limitadas suas funções participativas. Um elemento importante elencado pela autora nesse tema é a resistência de setores do movimento sindical a essas mudanças.

Nessa chave, a montagem das estruturas corporativas no que diz respeito ao setor trabalho não ocorre devido à ausência de conflito. No sentido também indicado por Gomes (1996), ao analisar o significado do conceito de populismo, a ação das organizações dos trabalhadores ao longo da construção do corporativismo não deve ser lida de forma exclusiva pela noção da manipulação das elites estatais. A noção de conflito em torno da expansão da participação na democracia brasileira está presente também nesse período, em que, de forma dual, presencia-se a demanda por direitos, via cidadania regulada, e a resistência dos setores populares à ação restritiva do Estado na questão participativa. Ou seja, mesmo que a tônica tenha sido a restrição à participação e à tentativa de manipulação das organizações da classe trabalhadora, é importante ressaltar que havia nesses setores resistência à ação estatal. De outro lado, em sentido diverso à relação com as classes trabalhadoras, permitiram-se às associações patronais instrumentos horizontais de diálogo, com inserção efetiva na condução das políticas estatais e permissividade de criação de organizações coletivas paralelas à estrutura oficial. Em síntese, a restrição à participação sobre o operariado e o diálogo e a inclusão na dinâmica estatal para o empresariado.

Os instrumentos coletivos de organização da classe operária reuniam as seguintes características: a) eram sindicatos e federações profissionais homogêneas, criadas pelo Estado; b) seu âmbito de organização era municipal; c) as arenas de acesso ao Estado se limitavam a burocracias do Ministério do Trabalho; e d) a interação com o Estado se dava de forma subordinada e hierarquizada, tendo como conteúdo reivindicações profissionais, sociais e trabalhistas.

As organizações patronais tinham como características: a) organizavam-se em sindicatos, federações e confederações setoriais, de formato heterogêneo, criadas pela própria classe e reconhecidas pelo Estado; b) o âmbito de atuação era estadual, regional e nacional; c) as arenas de acesso ao Estado se davam diretamente no Ministério do Trabalho e em arenas locais e federais de médio e alto nível; e d) a interação com o Estado se dava tanto de forma subordinada quanto de forma horizontal e paritária, com conteúdo de reivindicações político-econômicas, assessoramento, consulta e negociação (COSTA, 1999, p. 181).

Em síntese, Costa (1999) aponta que se construiu no Brasil uma modalidade excludente de corporativismo. Na relação com o setor trabalho, imperou a ação restritiva do Estado. Na relação com o empresariado, formou-se uma espécie de "corporativismo societal", aos moldes do modelo neocorporativo europeu, por meio do qual se combinou solução conjunta dos problemas de organização coletiva, a interferência desses grupos de interesse, a partir da estrutura estatal, em benefício próprio, a maior flexibilização organizacional e a autonomia da classe patronal. 
Portanto, o período em questão é marcado pela inclusão do Estado como arena factível de disputa política em torno de direitos sociais com base na noção de cidadania regulada. No entanto, a relação Estado-sociedade continuou marcada pelas diferenças históricas de recursos sociais e políticos entre as classes, o que impunha sobre os trabalhadores a tentativa de tutela e de controle organizacional pelas estruturas oficiais.

Em síntese, a história da construção do Estado no Brasil, ao longo dessa primeira fase do período republicano, assume como marca o conflito em torno da concretização do Estado como arena de participação política em que as respostas estatais são marcadas pela consagração da dinâmica restritiva. Em sua primeira fase, tal característica se dá pela ausência do Estado como espaço factível de materialização de direitos e de arena de representação política, restando aos setores populares a escassez de políticas públicas e forte repressão a seus processos associativos.

Na segunda fase, a partir da Revolução de 30, o Estado institucionaliza um padrão excludente de direitos partindo do conceito de cidadania regulada, articulando-o a mecanismos de representação corporativista impactados pela desigualdade de recursos entre os setores societários, em que pesava sobre as classes trabalhadoras estruturas corporativas com perspectiva limitantes à sua ação coletiva. Portanto, apesar da ampliação no que respeita ao reconhecimento de direitos seja marca do período desenvolvimentista em questão, no polo da participação política manteve-se a ação restritiva do Estado como principal característica.

\section{O NOVO CICLO DA PARTICIPAÇÃO}

\section{Redemocratização e novos padrões associativos}

A intermediação de interesses Estado-sociedade via estruturas corporativas persistiu hegemônica ao longo de todo o período desenvolvimentista. Tais estruturas, mesmo que com alterações pontuais, mantiveram sua essência, seja no período democrático de 1945-1964 diante de maior flexibilidade, que serviu à formação da base sindical do Partido Trabalhista do Brasil (PTB) e funcionou ao lado das instituições tradicionais de representação, seja no período ditatorial de 1964-1985, em que o polo estatal volta a se impor de forma decisiva sobre os atores societários (BOSCHI e DINIZ, 1989).

Boschi e Diniz (1989) apontarão o processo de redemocratização do país como processo de transbordamento dos limites institucionais definidos pelo Estado em sua trajetória desenvolvimentista de mediação das relações societais. O descolamento da trajetória associativa do empresariado das estruturas oficiais resultante do endurecimento do autoritarismo, a retirada de seu apoio político ao regime militar e o surgimento de novos atores sindicais, chamados de "novo sindicalismo", e novas tradições associativas são exemplos centrais da dinâmica da redemocratização no país. Como apontam os autores:

Como decorrência da modernização econômico-social, a sociedade terminou por extravasar dos limites institucionais definidos pelo Estado, por intermédio da formação de uma série de canais alternativos de participação e mecanismos adicionais de vocalização dos seus interesses. Não se trata apenas de mudanças de natureza quantitativa traduzidas na proliferação de grupos, mas do aumento dos graus de organização e de autonomia de uma série de segmentos, aí incluindo a classe trabalhadora (BOSCHI e DINIZ, 2004, p. 36-37).

Esse fenômeno será lido por Guimarães (2010) como o segundo grande ascenso da autoformação do povo brasileiro. O primeiro teria-se dado no processo de redemocratização pós-Estado Novo, tendo como marca o tema nacionalismo, e sendo encerrado com o fim da trama democrática advinda do golpe militar na década de 1960, como apontado na introdução deste artigo. A segunda fase teve início na resistência ao autoritarismo militar e se prolongaria como animadora da democratização do Estado brasileiro, "de forma contínua e inacabada, até os dias de hoje" (GUIMARÃES, 2010, p. 14). Para o autor, a redemocratização brasileira caminhou de forma conjunta a um forte processo de organização da sociedade civil, impulsionando a formação de movimentos como a Central Única dos Trabalhadores (CUT), o Movimento dos Trabalhadores Sem Terra (MST) e o próprio Partido dos Trabalhadores (PT), resultando em um processo, a partir desses atores, de potencial fortalecimento dos contornos democráticos da relação Estado e sociedade no Brasil. 
Cinco tradições animariam o segundo ciclo de mobilização e autoformação do povo brasileiro: o comunitarismo cristão; o nacional-desenvolvimentismo; o socialismo democrático; o liberalismo republicano; e a cultura popular. Como unidade dessas tradições, estaria o elemento que mais interessa a este trabalho: a defesa da democratização e da cidadania ativa. É possível pensar em diálogo, com a chave proposta por Guimarães (2010), na leitura de uma gama de autores acerca dos desafios da consolidação democrática no Brasil.

Por exemplo, o conceito de cidadania como estratégia política, proposto por Dagnino (1994), desdobra-se, de um lado, como expressão concreta dos atores envolvidos no processo de democratização; e, de outro, no compromisso fundamental dessa nova noção com o aprofundamento da democracia. Como aponta a autora: "a nova cidadania transcende uma referência central ao conceito liberal, que é a reivindicação de acesso [...] ao sistema político [...] o que está em jogo de fato é o direito de participar efetivamente" (DAGNINO, 1994, p. 109).

Avritzer (2002) elencará como elemento-chave à consolidação da democracia na América Latina a capacidade de transferir a renovação societal provocada pelo processo de "liberalização" no Brasil para espaços institucionais de deliberação e participação política, aproximando-se, portanto, da leitura de Guimarães (2012); ou seja, a transformação em instituições participativas das novas práticas emergentes da sociedade civil ao longo do processo de "abertura" do sistema político brasileiro é o núcleo ordenador, ainda em operação, da consolidação da democracia no país. Nas palavras do autor: "a questão central colocadas às teorias contemporâneas da democratização é a conversão de práticas democráticas que emergiram no arena publica em relações institucionais entre a atores civis e a sociedade política" (AVRITZER, 2002, p. 8, "tradução nossa").

O mérito em retomar a chave acima é a possibilidade de pensar de forma prolongada o ciclo de democratização brasileira. Seus limites não estão, apesar de sua importância, no estabelecimento e na estabilização da competição política eleitoral, mas em um processo longo em curso e inacabado de democratização do Estado brasileiro que envolve, de forma central, a experimentação de espaços institucionais de participação e deliberação direta na política.

Em síntese, ao longo da trajetória republicana brasileira, os conflitos em torno da expansão da participação emanada das organizações da sociedade civil esbarraram na ação restritiva do Estado, seja via repressão na Primeira República, seja via corporativismo nos anos seguintes. O contexto da redemocratização constitui um cenário distinto em que se ampliaram as possibilidades em converter tais demandas em instituições com maior potencial democrático.

O pano de fundo das interpretações desses autores elenca como chave desse novo contexto o surgimento de novos atores sociais com características associativas inovadoras. A literatura ressalta, sobretudo no que respeita à organização dos setores mais empobrecidos, um padrão mais autônomo em relação ao Estado. O gatilho desse processo de mudanças aponta para o caráter repressivo nas relações da sociedade com a experiência autoritária predecessora e para o processo de modernização econômica desordenada, baseada na migração da população rural para os centros urbanos e acompanhada da diminuição da qualidade dos serviços públicos, como saúde, educação e transporte (AVRITZER, 2012a; KERSTENETSKY, 2012; BOSCHI, 1987).

A ampliação e a diversificação do padrão associativo da sociedade brasileira é característica amplamente pesquisada na literatura acadêmica. A análise de Boschi (1987, p. 68) é pioneira nesse tema, apesar de limitada ao município do Rio de Janeiro. O autor registra que o número de associações de moradores cresceu 83\% no período de 1979-1981, sendo 65\% desse índice ligado a associações de áreas periféricas da cidade.

Santos (1993) ampliou o foco das análises indicando a ocorrência do mesmo fenômeno em outras grandes cidades brasileiras e abarcando de forma ampla as associações voluntárias. Baiocchi (2003) e Avritzer (2000) agregarão dados relativos a Porto Alegre e Belo Horizonte para o período em questão. 
Tabela 1

Número de associações voluntárias nas maiores cidades brasileiras

\begin{tabular}{|l|c|c|c|c|c|}
\hline Cidade & $1941-1950$ & $1951-1960$ & $1961-1970$ & $1971-1980$ & $1981-1990$ \\
\hline São Paulo & 288 & 464 & 996 & 1871 & 2553 \\
\hline Rio de Janeiro & 188 & 743 & 1093 & 1233 & 2497 \\
\hline Belo Horizonte & 120 & 204 & 459 & 584 & 1597 \\
\hline Porto Alegre & - & - & - & 240 & 380 \\
\hline
\end{tabular}

Fonte: Adaptada de Santos (1993), Avritzer (2012a) e Baiocchi (2003).

Os dados evidenciam o crescimento das associações voluntárias nas maiores cidades do país. Em São Paulo, o associativismo duplicou ao longo da década de 1970 e manteve esse crescimento de $36 \%$ na seguinte. Em Belo Horizonte, os números triplicaram ao longo da década de 1980; e no Rio de Janeiro, houve duplicação no mesmo período.

Interessante notar também que, para além da ampliação quantitativa, verificou-se também certa diversificação qualitativa, por exemplo, das associações comunitárias em São Paulo: 97,6\% foram criadas no período de 1970-1986, assim como 92,5\% das associações de profissionais de saúde e $90,7 \%$ das associações de moradores. No Rio de Janeiro, os números, para o período de 1971-1987, replicam a mesma tendência com 90,7\% para associações comunitárias, 85,3\% para moradores e 83\% para profissionais de saúde (SANTOS, 1993). Como aponta Santos (1993, p. 83): "Sociologicamente é possível inferir que, se pluralismo social quer dizer quebra do monopólio organizacional, foi precisamente isso o que ocorreu no país".

Avritzer (2009) agrega dados da distribuição por categoria em relação à cidade de Belo Horizonte. De acordo com ele, todas as associações que lidam com temas relacionados à proteção do meio ambiente, direitos humanos e questões étnicas na cidade surgiram ao longo da década de 1980.

É possível concluir, portanto, com a assertiva de que os principais centros urbanos brasileiros vivenciaram um crescente processo de associativismo ao longo do período da democratização, tanto no que diz respeito ao número das organizações quanto à sua diversificação temática. A reivindicação de autonomia perante as estruturas do Estado será uma forte marca desse novo impulso associativo brasileiro. Exemplos dessa característica estão no seu formato organizacional mais horizontalizado, no alto índice de participação voluntária nas associações e na defesa de maior participação da sociedade civil na implementação de políticas públicas (AVRITZER 2000; 2012a).

\section{Os adventos da redemocratização}

A conjuntura da redemocratização, caracterizada pela diminuição da legitimidade das elites estatais e pelo crescente processo organizativo da sociedade civil, permitiu que o conflito em torno da participação, presente ao longo de toda a trajetória republicana, tomasse um caminho diverso ao presenciado anteriormente. A partir desse período, a relação entre Estado e sociedade no Brasil assumirá três consequências centrais: a) estabilidade no que respeita à competição política-eleitoral; b) enfraquecimento das estruturas corporativas; e c) convivência com a busca e a experimentação em torno de inovações capazes de aprofundar a democracia brasileira.

A redemocratização no Brasil terá como característica a adoção de uma série de medidas para a consolidação da competição política-eleitoral, entre as quais a concessão de votos aos eleitores analfabetos, a liberalização das regras para a criação de novos partidos, as eleições diretas para cargos que haviam perdido a elegibilidade ao longo do período militar e a promulgação de uma nova Constituição (NICOLAU, 2012). Em 1989, dá-se início a um ciclo, contínuo até os dias atuais, de eleição direta à Presidência da República. Desde lá, ocorreram seis pleitos eleitorais para o cargo, sendo eleitos quatro presidentes distintos, tendo Itamar Franco assumido após o impeachment de Fernando Collor de Melo, ligados a quatro agremiações políticas com identidades e trajetórias diversas. No que respeita às outras entidades federativas em relação à competição eleitoral, a passagem de Nicolau (2012) é fundamental: 
No dia 1ㅇ de fevereiro [1990], data em que Fernando Collor de Melo tomou posse na Presidência da República, todos os cargos de chefes de Executivo no país (governadores, prefeitos) e de membros do Legislativo (senadores, deputados federais e estaduais e vereadores) eram ocupados por indivíduos escolhidos pelo voto popular. Vale a pena destacar que essa foi a primeira vez que tal fato acontecia na história do país (NICOLAU, 2012, p. 123).

Assim, a estabilização e a ampliação da competição eleitoral é marca central na redemocratização brasileira. O segundo impacto na relação entre Estado e sociedade será a fragilização das estruturas corporativas herdadas do período desenvolvimentista. As novas associações, por conta de sua reivindicação de autonomia, seus formatos e desejos organizativos e sua diversificação temática, procuraram constituir-se como oposição a esses mecanismos de representação de interesse, ou transbordaram seus limites, como propõem Boschi e Diniz (1989).

Sobretudo a partir do decênio de 1990, em que se tornou central a agenda da retração do papel do Estado na economia, seja via liberalização econômica e privatização, seja pela incapacidade de efetivar a agenda de direitos consagrados na Constituição (KERSTENETZKY, 2012), as estruturas corporativas são fortemente esvaziadas tanto na relação com o empresariado (BOSCHI e DINIZ, 2004) quanto nas tentativas de restrição à ação dos setores ligados ao trabalho (CARDOSO, 2003, p. 44).

É bem verdade que ocorreu, nas gestões Collor/Itamar, a tentativa de recompor estruturas corporativas distintas da característica dual do período desenvolvimentista, com criação das câmaras setoriais (COSTA, 1994). No entanto, a consolidação da agenda neoliberal, desde a eleição de Fernando Henrique Cardoso, interrompeu qualquer tentativa nesse sentido.

Sendo assim, a segunda consequência da redemocratização brasileira será o rompimento dos canais de representação constituídos ao longo da era desenvolvimentista, baseados nas estruturas corporativas e na desigualdade de recursos. De um lado, esse esvaziamento foi consequência de uma dinâmica de liberalização da economia brasileira, que encontrou forte resistência nas organizações sociais; de outro, o novo padrão associativo emergente na democratização não "cabia" nos marcos do corporativismo excludente/bifronte que dimensionou a trajetória brasileira. $O$ fortalecimento da sociedade civil em compasso com a redemocratização do país exigia e propunha, como se verá ao longo de todo o processo Constituinte, novas dinâmicas de relação com o Estado, em que o padrão corporativista que moldou o desenvolvimento brasileiro não conseguia responder.

O terceiro, e mais importante impacto para os fins deste artigo, consiste na criação de inovações participativas com o objetivo de ampliar as características democráticas da relação entre Estado e sociedade no Brasil. Tal elemento será uma das marcas da Assembleia Nacional Constituinte convocada em 1986, inaugurando o que Avritzer (2012a) classifica como uma segunda fase da formação da sociedade civil brasileira baseada no "aprofundamento democrático".

A ANC teve como característica a abertura e a presença organizadas dos setores em mobilização ao longo do processo de restabelecimento democrático, seja via pressão social, seja via de proposição de emendas populares. O principal resultado foi a impressão na Carta de 1988, e em sua subsequente legislação infraconstitucional, de inovações democráticas propostas com vistas a potencializar a participação e a gestão compartilhada de políticas públicas entre Estado e sociedade. Por exemplo, tanto na área de saúde quanto nas questões relacionadas à reforma urbana foram propostas emendas populares, no primeiro caso, com 61 mil assinaturas e, no segundo, com 131 mil, em que estavam presentes a perspectiva de fortalecimento da participação e a deliberação da população na arena pública. Ambas tiveram grande impacto em um viés fortemente participativo adotado pela Constituição em relação a esses temas, como o art. 198 em relação à saúde e à exigência de plano diretor na questão urbana pelo art. 181, desencadeando legislação infraconstitucional capaz de materializar essa dinâmica, vide a regulamentação dos conselhos e conferências de saúde pela Lei n. 8.142/1990 e a exigência de audiências públicas para aprovação do Plano Diretor das cidades previstas no Estatuto das Cidades, aprovado em 2001 (AVRITZER, 2012a). Para além das duas áreas, há também previsão participativa em relação à seguridade social (art. 194) e à assistência social (art. 203).

Vale ressaltar como essas áreas de políticas públicas, em que se obtiveram ampliações no que diz respeito à experimentação democrática, coincidem com os dados relativos à diversificação temática da criação de associações voluntárias apresentados por Santos (1993); ou seja, profissionais de saúde e organizações comunitárias que tiveram forte impulso associativo no processo de liberalização desembocaram na disputa por democratização do Estado na Constituinte.

Ainda para exemplificar, vale ressaltar que a Constituição Federal aprovada vai além da inclusão do viés participativo só em relação à gestão de políticas públicas. É possível destacar a previsão de outras modalidades de instrumentos de participação 
direta, como a previsão acerca dos direitos políticos do art. 14: “[a] soberania popular será exercida pelo sufrágio universal e pelo voto direto e secreto, com valor igual para todos, e, nos termos da lei, mediante: plebiscito, referendo [e] iniciativa popular". Nesse rol, incluem-se também a previsão de lei de iniciativa popular para todos os entes federados (arts. 27, 29 e 61), assim como a previsão de instrumentos jurídicos em defesa de direitos coletivos, como o mandado de segurança, a ação civil pública e a ação popular (art. 5).

Em síntese, o processo constitucional brasileiro teve como característica importante a ampla participação da sociedade civil em formação e em mobilização no período da redemocratização. Seu resultado será a inclusão da experimentação participativa no centro da Carta aprovada, abrindo caminho e, ao mesmo tempo, consolidando um vigoroso processo com o intuito de potencializar o aprofundamento da democracia brasileira. A nova Carta que marca a refundação democrática no Brasil caminhou lado a lado, sobretudo via pressão social, da nova sociedade civil emergente no contexto da redemocratização. A fase do "aprofundamento democrático" (AVRITZER, 2012a) deixou sua impressão na nova Carta constitucional.

A partir da dinâmica estabelecida na Constituição aprovada, dois novos espaços se abriram ao estabelecimento de novos contornos na relação entre Estado e sociedade. De um lado, o longo processo de efetivação dos mecanismos previstos na Carta Magna, o que envolve, sobretudo, a legislação infraconstitucional e o empoderamento desses institutos no nível local. De outro, o Estado brasileiro passa a adotar inovações democráticas que não tinham sido formalmente previstas no documento constitucional, entre as quais a mais famosa é o Orçamento Participativo.

Esse processo de "aprofundamento democrático" se deu com o funcionamento estável das instituições políticas tradicionais. Nesse sentido, uma das características dessa nova fase do processo de democratização da sociedade brasileira será a entrada em cena de um novo fenômeno. Trata-se da capacidade dos atores societais estabelecerem diálogos com aqueles envolvidos na arena da competição político-institucional, ou seja, construir pontes capazes de fazer convergir demandas participativas das organizações sociais e dos agentes envolvidos na disputa política eleitoral. A leitura proposta por Avritzer (2009) sobre o surgimento das instituições participativas terá como um de seus pontos centrais a compreensão dessa interação entre organização da sociedade civil e os partidos políticos, principais agentes da arena eleitoral, como elemento importante ao aprofundamento da agenda participativa ${ }^{1}$.

No Brasil, o PT será o principal veículo de canalização das demandas participativas para a arena da competição política. Como aponta Avritzer:

O PT foi crucial para trazer políticas participativas da periferia do sistema político ao seu centro. O PT era ator central ao final dos anos 80 nos debates sobre participação nos sistemas de saúde. Foi central também no processo de aprovação de processos participativos nas elaborações dos planos diretores das cidades brasileiras. O PT de Porto Alegre introduziu o orçamento participativo durante sua primeira gestão na administração da cidade (AVRITZER, 2009, p. 12-13, tradução nossa).

A inclusão do PT como variável explicativa na análise exige uma breve digressão sobre seu processo de organização. O PT pode ser considerado o primeiro partido de massas no Brasil ${ }^{2}$. Desenvolveu-se como opção na arena política dos principais atores envolvidos no impulso associativo da redemocratização, sobretudo ligados ao novo movimento sindical e aos movimentos populares vinculados a organizações de base da Igreja católica, além de contar com a migração de agrupamentos da esquerda que sobreviveram à ditadura militar e de parte da intelectualidade localizada principalmente em São Paulo, a partir do Centro Brasileiro de Análise e Planejamento (Cebrap), do Centro de Estudos de Cultura Contemporânea (Cedec), da Universidade de São Paulo (USP) e da Universidade Estadual de Campinas (Unicamp) (KECK, 1992; MENEGUELLO, 1989). Ao longo de suas três décadas de existência, constitui-se como a mais bem-sucedida experiência de partido de esquerda na

\footnotetext{
${ }^{1}$ O foco da análise de Avritzer (2009) será como a diferença de interação entre sociedade civil, atores políticos e desenho institucional afeta a efetividade das instituições participativas adotadas no nível local no Brasil. O ponto deste trabalho não é tratar das experiências locais de participação; por isso, o mais importante para os fins aqui propostos será a inclusão da variável partidária para a criação das instituições participativas, e não como a diversidade de interação das variáveis impacta em sua efetividade.

${ }^{2}$ A caracterização do surgimento do PT como primeiro partido de massas no Brasil, a partir do modelo de Duverger (1980), foi pioneiramente trabalhada por Meneguello (1989). Para sua assertiva, a autora destaca como características: origem extraparlamentar; estrutura interna baseada nos núcleos de base e integração com as direções partidárias; priorização dos laços com os movimentos sociais, tendo como proposta ideológica a inclusão dos setores marginalizados na arena política; e a existência de uma dinâmica de participação partidária para além dos momentos eleitorais. Cf. Meneguello (1989, p. 36)
} 
América Latina, sobretudo no que se refere à ocupação de espaços institucionais, partindo de gestões locais nas principais cidades do país ao longo das décadas de 1980 e 1990 até a chegada à Presidência da República em 2003.

Um dos traços que marcarão a identidade petista será a defesa da experimentação em torno da adoção de mecanismos de participação popular; ou seja, a onda democratizante da década de 1970, que gerou movimentos mais autônomos e marcados pela defesa de uma democracia ativa, também o faz no que respeita à constituição de novos agentes na arena da competição eleitoral, em especial sobre o PT.

Pogrebinschi (2012) apontará como esse tema estará presente desde os primeiros documentos partidários, como o Manifesto de Fundação do partido em 1980, até declarações mais recentes proferidas tanto ao longo dos três mandatos petistas na Presidência da República. Samuels (2004), com base em dados da pesquisa Instituto Superior de Estudos Brasileiros (Iseb) de 2002, indicará como traços da identidade petista a condenação de práticas clientelistas e a crença na participação política como fundamental para a mudança da sociedade, ou seja, mesmo vinte anos depois do início da redemocratização, mantém-se presente a convergência entre a identidade petista e o contorno participativo do novo ciclo associativo brasileiro.

Dados relacionados ao Orçamento Participativo também reforçam o quadro acima exposto, em especial pelo fato de a decisão de criá-lo ser exclusivamente do principal ator político local, o prefeito das cidades, ou seja, está intrinsecamente ligado às opções da arena política. A primeira experiência foi criada na administração petista de Porto Alegre, em fins da década de 1980, e até 1997 a grande maioria dessas experiências estava vinculada a administrações do PT. Nos anos seguintes, há um processo de diversificação, atingindo inclusive gestões comandadas por partidos de centro. Portanto, o impulso inicial desse mecanismo e sua consolidação como instrumento aliado à construção de uma cultura democrática no país esteve fortemente ligado ao PT (AVRITZER, 2010).

Vale ressaltar, também, que ocorreram processos semelhantes ao brasileiro em outras experiências latino-americanas. Sobretudo a partir do fim da década de 1990, com a eleição de Hugo Chávez na Venezuela, a América Latina vivenciou uma convergência entre a chegada da esquerda ao poder, novos processos constitucionais e a emergência de instituições participativas. Mesmo que nessa tradição mais recente haja como marca diferenciadora a emergência de novos processos constituintes a partir da chegada da esquerda ao poder, como nos exemplos da Bolívia, do Equador e da Venezuela, as variáveis em questão presentes nos países vizinhos uma década depois são semelhantes à dinâmica da trajetória brasileira: forte processo associativo; avanço da esquerda na institucionalidade; reforma constitucional e ampliação de instituições participativas (POGREBINSCHI, 2013).

Tais características reforçam a compreensão do PT como instrumento político eleitoral em torno do qual se articulou a agenda das inovações democráticas no Brasil. Os dois vetores propostos aqui para a compreensão do fenômeno, a materialização de instrumentos previstos na Constituição de 1988 e a inventividade em torno de novos mecanismos de participação, conjugaram-se com atores presentes na arena da competição política a fim de ser concretizados. Nesse processo, um elemento importante foi o avanço do PT na arena eleitoral. Por isso, essa agenda se materializou, sobretudo no nível local, ao longo da década de 1990, com a forte expansão dos conselhos ligados a alguns temas de políticas públicas e à criação do Orçamento Participativo (AVRITZER, 2009; ABERS, 2000; BAIOCCHI, 2003). Ademais, sua ampliação em escala nacional foi impulsionada a partir de 2003, com a vitória de Luis Inácio Lula da Silva para a Presidência da República.

\section{O NOVO IMPULSO NACIONAL}

A chegada do PT à Presidência da República pode ser, e tem sido, objeto de análise sob diversos matizes, em especial devido à sua importância histórica. Para além de significar a inédita chegada de um partido forjado a partir do processo de mobilização social externa à arena política ao posto mais alto da institucionalidade nacional, seu principal símbolo é a consolidação da democracia brasileira. Era a primeira vez, desde a redemocratização, que um presidente eleito pelo voto popular passava o cargo a outro escolhido pelo mesmo processo.

Não cabe aqui uma pesquisa sobre a totalidade dessas análises e significados, positivos ou negativos, da experiência brasileira de chegada de uma frente de esquerda à Presidência. O ponto que interessa é como esse fenômeno gerou um novo impulso no processo de experimentação democrática no país, porém ampliada em escala nacional. 
Ao longo da década de 1990, a disputa em torno do experimentalismo democrático no país esteve, sobretudo, associada ao nível local. Como se apontou aqui, tal período é marcado pela hegemonia do neoliberalismo e por sua agenda de retração do papel do Estado na economia. De forma concomitante, conviveu-se com um processo de experimentação democrática, em especial no nível local, impulsionada pela criação do orçamento participativo e pela regulamentação de dispositivos constitucionais. Nesse contexto, a efervescência da participação local não encontrou respaldo ou autores decididos a incorporar a agenda das inovações democráticas em experiências nacionais de ampliação da participação da sociedade. A exposição de Avritzer (2012b, p. 21) sobre o tema é precisa:

Não existem dúvidas de que nos 15 primeiros anos de vigência do texto constitucional foi estabelecida uma divisão de trabalho através da qual a representação prevaleceu no âmbito do governo federal, ao passo que a participação se fortaleceu localmente pela via dos orçamentos participativos e da participação nos conselhos. Essa divisão de trabalho informal terminou com a chegada do PT à Presidência da República e a enorme ampliação das conferências nacionais.

A chegada do PT ao Executivo federal e a expansão de inovações democráticas podem ser lidas como consequência de tendência partidária a investir na adoção de instrumentos de participação direta do cidadão na política. É a materialização da trajetória de experimentação que marca o contexto de formação do PT, agregado ao desafio de constituir-se nacionalmente.

No entanto, é fundamental ressaltar os estudos que indicam que o PT não ficou imune à ampliação de sua participação institucional, como aponta Ribeiro (2010), ao indicar que o partido se tornou mais próximo do Estado e com vínculos mais frouxos com a sociedade, comparando sua conjuntura com aquela identidade como partido de massas da sua formação (MENEGUELLO, 1989). Nessa assertiva, Ribeiro (2010, p. 213-214) apoia-se, sobretudo, em questões ligadas ao financiamento partidário e ao processo de fortalecimento de um padrão de profissionalização política apoiada quase exclusivamente em esferas e recursos estatais.

Nessa chave, abrem-se as possibilidades de pesquisar se o impulso nacionalizante, dado a partir de 2003, converge ou se distancia do modo petista de governar, que marcou as primeiras gestões petistas e tem a participação como elemento central, como propõe Samuels (2009). A conclusão do autor é que a chegada do PT frustrou o horizonte de expectativas colocado nesse tema, em especial ao não indicar para a construção da experiência do Orçamento Participativo em nível nacional. Apesar da importância de tais questões, o ponto central deste artigo não é a análise do impacto do Estado na trajetória petista, nem um estudo sobre a questão partidária em si. No entanto, o arcabouço sociológico e histórico apresentado neste trabalho pode auxiliar as pesquisas futuras a compreender o contexto, os limites e as possibilidades colocados em um eventual impulso mais agudo em torno de inovações democráticos como o autor defende que se constituiria o modo petista de governar. No artigo em questão, Samuels (2009) não explora tais elementos, o que acaba por tornar limitada sua assertiva acerca da frustação em torno das expectativas da chegada do PT à Presidência da República.

Não é objetivo deste trabalho analisar cada inovação introduzida nesse impulso nacional. Nossa perspectiva central é desvendar como se constituíram tais experiências concentrando foco maior nos aspectos históricos da formação do Estado brasileiro. No entanto, é indispensável, para a melhor compreensão do fenômeno em discussão, citar brevemente quais as principais inovações democráticas constituídas na última década. Três grupos de mecanismos destacam-se.

Em primeiro lugar, a criação de instrumentos mais transparentes de diálogo com a sociedade. Nesse sentido, destaca-se a potencialização das ouvidorias, sendo criadas 84 nos três primeiros anos de mandato, o uso de audiências públicas na condução de ações do governo e a criação de mesas permanentes de negociação para dialogar com a sociedade civil (SOUZA, 2008; LAMBERTUCCI, 2010). Em segundo, presenciou-se um forte impulso na constituição e no empoderamento de conseIhos nacionais de políticas públicas com participação compartilhada entre Estado e sociedade civil na execução, na gestão e na consulta sobre as políticas. Nesse aspecto, o governo petista ficou marcado, primeiro, pela ampliação no número de conselhos. Segundo dados oficiais ${ }^{3}$, o Brasil tinha, até 2010, 39 conselhos nacionais, dezenove dos quais criados nos dois mandatos petistas no Executivo federal. Além disso, a literatura sobre o tema aponta que há um processo de fortalecimento desses fóruns, exemplificados na maior participação dos ministros em suas reuniões, na revisão de regras para a participação da sociedade civil e na ampliação da sua previsão orçamentária (AVRITZER, 2010; CUNHA, 2010). Em terceiro, a principal inovação nesse contexto foram as Conferências Nacionais de Políticas Públicas (CNPP). A literatura sobre o tema é consensual nesse

\footnotetext{
${ }_{3}^{3}$ Disponível em: <http://www.secretariageral.gov.br/noticias/Publi/guia-conselhos-nacionais-2013>. Acessado em: 25 de outubro de 2014.
} 
reconhecimento em torno das CNPP. Para Avritzer (2012a, p. 7), "a realização de um conjunto de conferências [...] constituiu uma marca registrada do governo Lula". Pogrebinschi (2012, p. 2) indica que "dos diversos mecanismos participativos adotados ao longo dos dois mandatos de Lula, as conferências nacionais de políticas públicas (comumente denominadas apenas como 'conferências nacionais') são certamente as de maior amplitude". Por se constituir como mecanismo nacional de participação, em geral antecedida de etapas estaduais, regionais e municipais, as conferências têm caráter mobilizador mais amplo que outros experimentos. Avritzer (2009) aponta que, até 2004, mais de 300 mil pessoas participaram da experiência do Orçamento Participativo no Brasil e 400 mil dos espaços de Conselho de Saúde e Assistências Social. Dados oficiais ${ }^{4}$ indicam que as Conferências, só no período de 2003-2010, reuniram aproximadamente 5 milhões de brasileiros. Ou seja, ampliou-se exponencialmente a capacidade de a população participar politicamente por meio dessa inovação ${ }^{5}$.

À guisa de conclusão, tomadas em conjunto, essas experiências foram responsáveis por abrir canais inéditos de diálogo entre a sociedade civil e o Estado, reconhecer na participação social um caminho para a elaboração de políticas públicas, potencializar a capacidade da sociedade brasileira de apresentar agendas e demandas políticas ao Estado brasileiro e permitir a participação e a deliberação de milhões de cidadãos em espaços institucionais reconhecidos pelo Estado. Tais inovações colocam o tema participação em um patamar diferenciado no que respeita à sua trajetória histórica no contexto nacional, rompendo com processos restritivos de participação política no país e ampliando o escopo desse tema para novos arcabouços institucionais.

\section{CONSIDERAÇÕES FINAIS}

A proposta deste artigo era contribuir para a compreensão de um fenômeno absolutamente contemporâneo: o surgimento de inovações institucionais com fins de ampliar as características participativas e deliberativas das democracias. Como base para esse processo tomou a análise da trajetória participativa do Estado brasileiro e sua relação com a sociedade.

Buscamos explorar como o conflito em torno da participação política no Brasil, ao longo do período republicano, culminou na construção de uma democracia marcada atualmente por índices estáveis de competição política e, sobretudo, por uma diversidade analisada internacionalmente de inovações democráticas participativas e deliberativas. Em certo sentido, procuramos apresentar os percalços da dinâmica participativa no Brasil, apontando dados e elementos importantes no contexto histórico e sociológico da formação do Estado brasileiro, sua relação com a expansão da participação e a constituição de inovações democráticas.

A literatura acadêmica sobre esse tema tem dedicado seus esforços em compreender como tais mecanismos podem aprofundar ou ampliar a qualidade das democracias, avaliando seu potencial de impactar características como responsividade, accountability, participação e igualdade. Este artigo seguiu caminho distinto ao enfocar mais os aspectos históricos do que a análise dos resultados e a efetividade dessas inovações.

Há diversos benefícios possíveis a partir desse caminho. O percurso histórico retomado aqui pode ajudar, por exemplo, a investigar a pluralidade da participação nessas inovações e agregar mais elementos à tradicional análise da autonomia/cooptação da sociedade civil pelo Estado. De forma mais específica, seria possível supor a existência de autonomia plena dos movimentos sociais e da sociedade civil na interação com o Estado nas arenas participativas diante da trajetória de regulação e de corporativismo que marcam a construção da cidadania no Brasil? Essa autonomia pode conviver com a forte presença do PT na sociedade civil brasileira e seu papel de impulsionador dessas experiências? Análises semelhantes podem ser elaboradas com base no potencial desses experimentos em constituir uma dinâmica igualitária. Outra vez com exemplos concretos: tais inovações democráticas teriam condições de romper com a trajetória do acesso desigual ao Estado por parte da sociedade? Qual o impacto da inclusão de setores historicamente alijados da relação entre Estado e sociedade em arenas participativas? Para refutar tais questões, o que acredito que parte da literatura tem-se dedicado a fazer (AVRITZER, 2009; POGREBINSCHI e VENTURA, 2014) ou confirmá-las, o percurso histórico aqui apresentado pode servir como elemento central. Todas são perguntas em aberto, não sendo objetivo deste trabalho procurar respostas conclusivas. A expectativa é de que a análise feita aqui auxilie produções futuras a respondê-las.

\footnotetext{
${ }^{4}$ As informações são da Secretaria Geral da Presidência da República. Disponível em: <http://www.secretariageral.gov.br/noticias/ultimas_noticias/2012/01/1001-2012-conferencias-mobilizaram-2-milhoes-de-pessoas-em-2011>. Acessado em: 25 de outubro de 2014.

${ }^{5}$ É possível afirmar que o esforço para expandir em nível nacional a participação política via inovações democráticas também se fez presente na terceira gestão petista à frente do Executivo federal. Os decretos de criação da Política Nacional de Participação e do Sistema Nacional de Participação Social são exemplos dessa continuidade.
} 


\section{REFERÊNCIAS}

ABERS, R. Inventing local democracy: grassroots politics in Brazil. Boulder, CO: Lynne Rienner, 2000.

AVRITZER, L. Democratization and changes in the pattern of association in Brazil. Journal of Interamerican Studies and World Affairs, v. 42, n. 3, p. 59-76, 2000.

AVRITZER, L. Democracy and the public space in Latin America. Princeton, NJ: Princeton University Press, 2002.

AVRITZER, L. Participatory institutions in democratic Brazil. Baltimore, MD: John Hopkins University Press, 2009.

AVRITZER, L. Sociedade civil e participação no Brasil democrático. In: AVRITZER, L. (Org.). Experiências nacionais de participação social. Belo Horizonte: Cortez, 2010. 7-12 p.

AVRITZER, L. Sociedade civil e Estado no Brasil: da autonomia à interdependência política. Opinião Pública, v. 8, p. 383-398, 2012a.

AVRITZER, L. Conferências Nacionais: ampliando e redefinindo os padrões de participação social no Brasil. Brasília, DF: Ipea, 2012b. (Texto para Discussão, n. 1).

AVRITZER, L.; SOUZA, C. H. L. (Org.). Conferências nacionais: atores, dinâmicas participativas e efetividade. Brasília, DF: Ipea, 2013.

BAIOCCHI, G. Radicals in power: the Workers' Party and experiments in urban democracy in Brazil. London: Zed, 2003.

BOSCHI, R. A arte da associação. Rio de Janeiro: Vértice, 1987.

BOSCHI, R. Corporativismo societal, a democratização do Estado e as bases social-democratas do capitalismo brasileiro. Insight Inteligência, v. 48, p. 1-20, 2010.

BOSCHI, R.; DINIZ, E. A consolidação democrática no Brasil: atores políticos, processos sociais e intermediação de interesses. In: DINIZ, E.; BOSCHI, R.; LESSA, R. Modernização e consolidação democrática no Brasil: dilemas da nova república. Rio de Janeiro/São Paulo: IUPERJ/Vértice, 1989. 23-37 p.

BOSCHI, R.; DINIZ, E. O corporativismo na construção do espaço público. IN: BOSCHI, R. (Org.). Corporativismo e desigualdade: a construção do espaço público no Brasil. Rio de Janeiro. Rio Fundo Editora, 1991. 3-21 p.

BOSCHI, R.; DINIZ, E. Empresários, Interesses e Mercado: Dilemas do Desenvolvimento no Brasil. Belo Horizonte, Ed UFMG, 2004.

CARDOSO, A. M. A década neoliberal e a crise dos sindicatos no Brasil. São Paulo: Boitempo, 2003.

CARDOSO, A. M. A construção da sociedade do trabalho no Brasil. Rio de Janeiro: FGV, 2010.

COSTA, V. R.; A Armadilha do Leviatã: A Construção do Corporativismo no Brasil. Rio de Janeiro: Editora UERJ, 1999.

COSTA, V. R. Corporativismo Societal: interesse setorial versus interesse de classe. In: DAGNINO, Evelina. (Org.). Anos 90: Política e Sociedade no Brasil. 1. ed. Campinas: Brasiliense, 1994. 75-99 p.

CUNHA, E. S. M. Inclusão social e política: o desafio deliberativo dos conselhos municipais de Assistência Social. In: AVRITZER, L. (Org.). A dinâmica da participação local no Brasil. São Paulo: Cortez, 2010. 93-128 p.

DAGNINO, E. Os movimentos sociais e a emergência de uma nova noção de cidadania: In: DAGNINO, E. (Org.). Os anos 90: política e sociedade no Brasil. São Paulo: Brasiliense, 1994. 103-115 p.

DAHL, R. Polyarchy: participation and opposition. New Haven, CT/ London: Yale University Press, 1971.

DUVERGeR, M., Os Partidos Políticos, Brasília: Ed. da UnB, 1980.

FUNG, A.; WRIGHT, E. O. Deepening democracy: institutional innovations in empowered participatory governance. London: Verso, 2003.

GEISSEL, B.; NEWTON, K. Evaluating democratic innovations: curing the democratic malaise. London: Routledge, 2012.

GOMES, A. C. O populismo e as ciências sociais no Brasil: notas sobre a trajetória de um conceito. Tempo, v. 1, n. 2, p. 59-72, 1996.

GUIMARÃES, J. Culturas brasileiras da participação democrática. In: AVRITZER, L. (Org.). Experiências nacionais de participação social. Belo Horizonte/São Paulo: UFMG/Cortez, 2010. 13-26 p.

KECK, M. The workers' party and democratization in Brazil. New Haven: Yale University Press, 1992.

KERSTENETZKY, C. L. O Estado do bem-estar social na idade da razão: a reinvenção do Estado social no mundo contemporâneo. Rio de Janeiro: Elsevier, 2012.

LAMBERTUCCI, A. R. A participação social no Governo Lula. In: AVRITZER, L. (Org.). Experiências nacionais de participação social. Belo Horizonte/São Paulo: UFMG/Cortez, 2010. 70-89 p.

LEAL, V. N. Coronelismo, enxada e voto. Rio de Janeiro: Forense, 1948.

MANSBRIDGE, J. Beyond adversary democracy. Chicago, IL: University of Chicago Press, 2003.

MANSBRIDGE, J.; PARKINSON, J. Deliberative systems: deliberative democracy at the large scale. Cambridge: Cambridge University Press, 2012. 1-26 p.

MENEGUELLO, R. PT: a formação de um partido, 1979-1982. Rio de Janeiro: Paz e Terra, 1989.

NICOLAU, J. Eleições no Brasil: do Império aos dias atuais. Rio de Janeiro: Zahar, 2012.

PATEMAN, C. Participation and democratic theory. London: Cambridge University Press, 1970.

POGREBINSCHI, T. Participação como método democrático de gestão. As conferências nacionais de políticas públicas durante o Governo Lula. 2012. Disponível em: <http://www.academia.edu/8820020/ Participa\%C3\%A7\%C3\%A3o_como_m\%C3\%A9todo_democr\%C3\%A1tico_de_gest\%C3\%A3o>. Acesso em: 13 dez. 2015.

POGREBINSCHI, T. The pragmatic turn of democracy in Latin America. Berlin: FES Studies on Latin America, 2013.

POGREBINSCHI, T.; SANTOS, F. Participação como representação: o impacto das Conferências Nacionais de Políticas Públicas no Congresso Nacional. Dados: Revista de Ciências Sociais, v. 54, n. 3, p. 259-305, 2011. 
POGREBINSCHI, T.; VENTURA, T. Responsividade democrática. O potencial das conferências nacionais de políticas públicas na democracia brasileira. In: ENCONTRO NACIONAL DA ABCP, 9., 2014, Brasília. [s.n]. Brasília, DF: ABCP, 2014.

SAMUELS. D. As bases do petismo. Opinião Pública, v. 10, n. 2, p. 221-241, 2004

SAMUELS, D. A democracia brasileira sob o governo de Lula e do PT. In: ANGELO, V. A.; VILLA, M. A. O Partido dos Trabalhadores e a política brasileira (1980-2006): uma história revisitada. São Carlos, SP: Ed. UFSCar, 2009. 135-154 p.

SANTOS, W. G. Cidadania e Justiça. Rio de Janeiro: Campus, 1979.

SANTOS, W. G. Razões da desordem. Rio de Janeiro: Rocco, 1993.

SCHUMPETER, J. Capitalismo, socialismo e democracia. Rio de Janeiro: Zahar, 1984.

SEELE, A.; PERUZZOTI, E. Participatory innovation and representative democracy in Latin America. Baltimore, MD: Woodrow Wilson Press/John Hopkins University Press, 2009.
SMITH, G. Democratic innovations: designing institutions for citizen participation. Cambridge: Cambridge University Press, 2009.

SOUZA, C. H. L. Partilha de poder decisório em processos participativos nacionais. 152 f. Dissertação (Mestrado em Ciência Política) Universidade de Brasília, Brasília, 2008.

RIBEIRO, P. F. Dos sindicatos ao governo. A organização nacional do PT de 1980 a 2005, São Carlos: Edufscar, 2010

URBINATI, N. Representative democracy: principles and genealogy. Chicago, IL: Chicago University Press, 2006.

VENTURA, T. Democracia e participação no Brasil: um estudo de caso das conferências nacionais de políticas públicas de 2003-2010. Dissertação (Mestrado). Universidade do Estado do Rio de Janeiro. Instituto de Estudos Sociais e Políticos, 2013.

VIANNA, L. W. Liberalismo e sindicato no Brasil. Belo Horizonte: Ed. UFMG, 1999. 